\title{
Topside ionospheric vertical electron density profile reconstruction using GPS and ionosonde data: possibilities for South Africa
}

\author{
P. Sibanda ${ }^{1,2,3}$ and L. A. McKinnell ${ }^{1,2}$ \\ ${ }^{1}$ Hermanus Magnetic Observatory, Hermanus, South Africa \\ ${ }^{2}$ Department of Physics and Electronics, Rhodes University, Grahamstown, South Africa \\ ${ }^{3}$ Atmospheric, Oceanic and Space Sciences, University of Michigan, Ann Arbor, USA
}

Received: 18 August 2010 - Revised: 24 November 2010 - Accepted: 13 January 2011 - Published: 2 February 2011

\begin{abstract}
Successful empirical modeling of the topside ionosphere relies on the availability of good quality measured data. The Alouette, ISIS and Intercosmos-19 satellite missions provided large amounts of topside sounder data, but with limited coverage of relevant geophysical conditions (e.g., geographic location, diurnal, seasonal and solar activity) by each individual mission. Recently, methods for inferring the electron density distribution in the topside ionosphere from Global Positioning System (GPS)-based total electron content (TEC) measurements have been developed. This study is focused on the modeling efforts in South Africa and presents the implementation of a technique for reconstructing the topside ionospheric electron density $\left(N_{\mathrm{e}}\right)$ using a combination of GPS-TEC and ionosonde measurements and empirically obtained Upper Transition Height (UTH). The technique produces reasonable profiles as determined by the global models already in operation. With the added advantage that the constructed profiles are tied to reliable measured GPS-TEC and the empirically determined upper transition height, the technique offers a higher level of confidence in the resulting $N_{\mathrm{e}}$ profiles.
\end{abstract}

Keywords. Ionosphere (Mid-latitude ionosphere; Modeling and forecasting)

\section{Introduction}

Relative scarcity of experimental topside ionospheric data (Benson et al., 1998) greatly limits the efforts to study this ionospheric region as a function of altitude and geographical location as well as diurnal, seasonal and solar activity variations. Ground-based ionosondes can only measure the

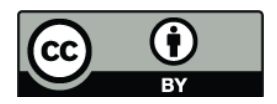

Correspondence to: P. Sibanda (malandisa@gmail.com) bottomside ionosphere, up to the height of the F2-peak. Measuring the topside ionosphere requires an ionosonde on board a satellite sounding from above the F2-peak. Only a few such missions, such as Alouette- $1 \&-2$, ISIS- $1 \&-2$ and Intercosmos 19, have been undertaken and have provided sets of topside ionospheric data, but with limited spatial coverage over a wide range of geophysical conditions. Further, only a small percentage of the total soundings were processed into electron density profiles (Huang et al., 2002), and coverage of the South African region is sparse within the processed database. Table 1 shows an example of how irregularly sampled the processed datasets are over the Southern African region. The table shows how the processed ISIS-2 topside sounder $N_{\mathrm{e}}$ profiles for the South African region are distributed over the four year period for which data were processed.

The small amount of measured topside ionospheric data available for the South African region and its irregular distribution over the various geophysical conditions posses a challenge in the efforts to model the topside ionosphere over this region. The data are not sufficient to properly characterise the structure of the topside ionosphere in terms of altitude distribution of the electron density $\left(N_{\mathrm{e}}\right)$ as well as its behavior due to diurnal, seasonal, solar activity and geomagnetic activity effects. This, therefore, brings to the fore the need to use other data sources for topside ionospheric $N_{\mathrm{e}}$ modeling in this region. Currently the most widely used ionospheric model to predict the topside $N_{\mathrm{e}}$ profile in the South African region is the International Reference Ionosphere (IRI) model. Ground-based ionosondes also provide an estimation of the topside $N_{\mathrm{e}}$ profile based on bottomside ionosphere measurements (Reinisch and Huang, 2001; Huang and Reinisch, 2001).

Since the mid 1990s, the Global Positioning System (GPS) has been used as a tool for ionospheric characterisation. In particular, GPS observations provide a measure of the ionospheric Total Electron Content (TEC). GPS-TEC, the integral value of the electron density along a ray path between

Published by Copernicus Publications on behalf of the European Geosciences Union. 
Table 1. Available topside sounder $N_{\mathrm{e}}$ profiles from the ISIS-2 satellite. The table indicates the number of $N_{\mathrm{e}}$ profiles available for each month (Sibanda and McKinnell, 2009).

\begin{tabular}{ccccc}
\hline & 1972 & 1973 & 1974 & 1975 \\
\hline Jan & - & - & 17 & - \\
Feb & - & 2 & - & - \\
Mar & - & 184 & - & - \\
Apr & - & 54 & - & - \\
May & - & - & - & - \\
Jun & - & 121 & - & 85 \\
Jul & - & 1 & - & - \\
Aug & 19 & 1 & - & 1 \\
Sep & - & 312 & - & 52 \\
Oct & - & - & - & - \\
Nov & - & - & - & - \\
Dec & - & 148 & - & 1 \\
\hline
\end{tabular}

the satellite and the receiver is an important characteristic of the Earth's ionosphere. It carries information on time and position variability of the ionosphere and has proved to be useful as a sensor of ionospheric climatology (Davies and Hartmann, 1997; Jakowski et al., 2004; Rama Rao et al., 2006). Applications include data assimilation techniques in ionospheric modeling whereby, the GPS-TEC can be used to adapt models for the locations and epochs of interest. The relatively dense coverage of GPS observations and the capability to provide continuous measurements make this a promissing tool for retrieving ionospheric features under different conditions (e.g., Yizengaw et al., 2006).

In the case of South Africa, the Chief Directorate Surveys and Mapping (CDSM) has over the recent past set up a network of dual-frequency continuously operating GPS base stations (Trignet network) distributed throughout South Africa at approximately a $200-300 \mathrm{~km}$ spacing (see Fig. 1).

The data are available to the scientific community through the anonymous ftp site at ftp.trignet.co.za and have presented unprecedented opportunities for ionospheric studies and characterisation. The GPS-TEC measurements provide a new data resource that can be used with other ionospheric measurements to monitor the actual state of the ionosphere continuously and to characterise the structure of the topside ionospheric $N_{\mathrm{e}}$ reliably in this region.

However, such satellite to ground-based receiver measurements can only produce information about the density in the form of path integrated snap-shots of the TEC and does not convey any information about the vertical distribution of the $N_{\mathrm{e}}$. The challenge is to decorrelate this to generate the vertical distribution of $N_{\mathrm{e}}$. In recent years, several techniques that use GPS-TEC to provide vertical profiling of the $N_{\mathrm{e}}$ in the ionosphere have been developed. These include:

1. Ionospheric tomography, a technique for imaging the vertical cross section through ionospheric $N_{\mathrm{e}}$. GPS-

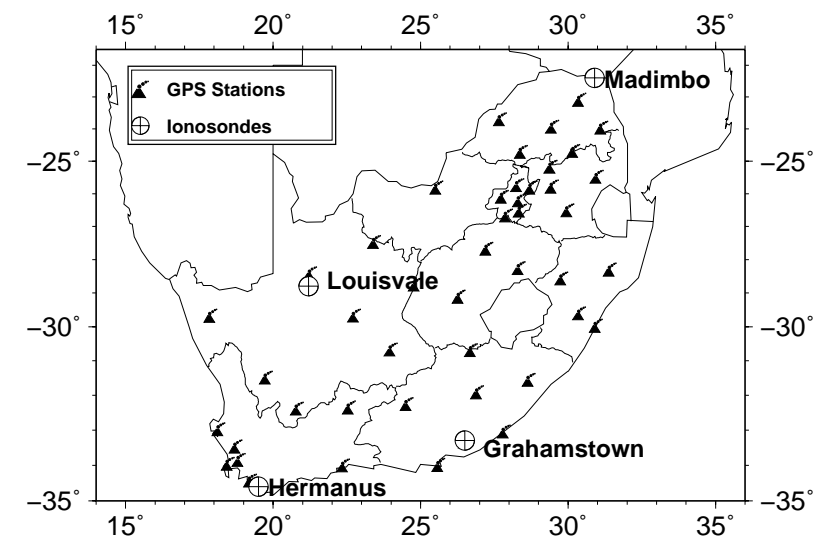

Fig. 1. CDSM GPS network and the four ionosondes are indicated. Note the co-located GPS receivers at Grahamstown, Louisvale and Hermanus ionospheric stations.

TEC values are used together with tomographic reconstruction algorithms to decompose the TEC into the different values of the $N_{\mathrm{e}}$ in the vertical for a relevant scenario (Sutton and Na, 1996; Yizengaw et al., 2007). To achieve this, a priori information about the ionosphere is added to the method, typically from a range of background ionospheres (for example, from a background model) representing many possible peak heights.

2. GPS Radio occultation. This occurs when a transmitting GPS satellite, setting or rising behind the Earth's limb, is viewed by a Low Earth Orbiting (LEO) satellite. As this happens, the relative motion between the GPS and LEO satellites sample the Earth's ionosphere at different altitude levels providing vertical $N_{\mathrm{e}}$ profiles from the LEO satellite orbit height down to the bottomside (Hajj and Romans, 1998; Jakowski et al., 2002).

This paper follows an approach proposed by Stankov and Muhtarov (2001). The method employs the use of complementary data sources (ionosonde measurements and the Upper Transition Height (UTH) values from a model) in addition to the GPS-TEC, in order to decorrelate the ionospheric layers in the vertical direction. The $N_{\mathrm{e}}$ at each point of calculation is represented as a sum of the constituent ion densities based on a key assumption that the ionosphere is statistically neutral and that the ions are singly charged. The density distributions of each individual constituent ions in the topside ionosphere are approximated by a standard profile function, such as Chapman, Epstein, or exponential. Approximating the distribution of the individual ions separately instead of the $N_{\mathrm{e}}$ directly, allows for the use of the UTH as an anchor point to shape the topside profile. Thus, using the conditions at the F2-peak and the conditions at the UTH, a system of equations is constructed from which the profile function is determined. The construction of the topside profile is based on the knowledge of the ionospheric parameters described in 
the section that follows resulting in a profile that is unique to a specific set of geophysical conditions. Therefore, the focus of the present study is on the ability to construct the shape of the electron density in the vertical.

\section{Input data for use in the reconstruction procedure}

The method was implemented for a single station, Grahamstown $\left(33.3^{\circ} \mathrm{S}, 26.5^{\circ} \mathrm{E}\right)$, South Africa, where a GPS receiver and an ionosonde are co-located. Preliminary results for the implementation using the Epstein function (Eq. 1) to approximate the individual ion density distributions are presented.

$N_{j}(h)=N_{j}(h m \mathrm{~F} 2) \operatorname{sech}^{2}\left(\frac{h-h m \mathrm{~F} 2}{2 H_{j}}\right)$

where $N_{j}$ and $H_{j}$ are the ion density and scale heights for the $j$-th ions, $h$ is the altitude and $h m \mathrm{~F} 2$ is the height of the F2peak. The concept of using Epstein functions as an analytical scheme for reproducing the vertical distribution of the $N_{\mathrm{e}}$ in the topside ionosphere has been applied in various modelling efforts (e.g. Booker, 1977; Radicella and Leitinger, 2001; Pulinets et al., 2002; Depuev and Pulinets, 2004). When the key parameters related to the ionospheric characteristics of the F2-peak are inserted, the Epstein function gives the vertical shape of the density profiles. In this study, the use of the Epstein function in the construction of the topside profiles is based on the measured values of GPS-TEC, $h m \mathrm{~F} 2$, peak $N_{\mathrm{e}}$ $(N m \mathrm{~F} 2)$ and the UTH described below.

\subsection{GPS-TEC measurements}

The GPS-TEC values were derived using the Adjusted Spherical Harmonic Analysis (ASHA) algorithm described in Opperman (2007). The algorithm is designed to detect and remove or correct signal outliers and signal cycle slips in the preprocessing of the GPS data (Opperman et al., 2007; Opperman, 2007). In addition, the procedure also corrects for receiver and satellite (instrument) biases in the derived TEC data and only considers TEC observations with elevation angles above $20^{\circ}$ to avoid multipath effects.

\subsection{Ionosonde measurements}

The ionosonde at the Grahamstown $\left(33.3^{\circ} \mathrm{S}, 26.5^{\circ} \mathrm{E}\right)$ ionospheric station was used to provide the bottomside ionospheric parameters; i.e., the peak $N_{\mathrm{e}}(N m \mathrm{~F} 2)$, the height of the peak $(h m \mathrm{~F} 2)$ and the bottomside ionospheric TEC $\left(\mathrm{TEC}_{\mathrm{b}}\right)$. The vertical GPS-TEC measurements are split into two contributions, one due to the bottomside ionosphere $\left(\mathrm{TEC}_{\mathrm{b}}\right)$ and the other due to the topside ionosphere $\left(\mathrm{TEC}_{\mathrm{t}}\right)$ as:

$\mathrm{TEC}_{\mathrm{t}}=\mathrm{GPS}-\mathrm{TEC}-\mathrm{TEC}_{\mathrm{b}}$

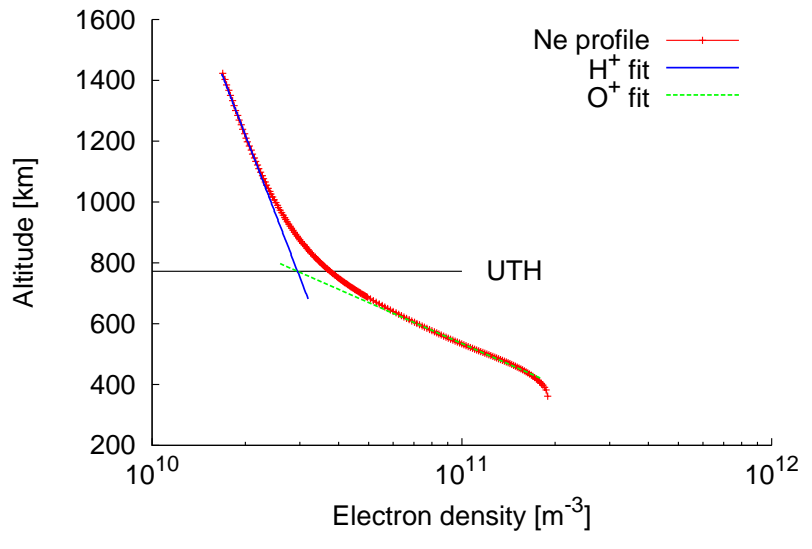

Fig. 2. The upper transition height determined by fitting the $\mathrm{O}^{+}$ regression line at the bottom part and the $\mathrm{H}^{+}$regression line at the top part of the $N_{\mathrm{e}}$ profile on a logarithmic $\left(\ln \left(N_{\mathrm{e}}\right)\right)$ scale.

\subsection{Upper Transition Height}

The UTH is another key parameter in this approach. This height lies in the transition region from a predominantly $\mathrm{O}^{+}$ topside ionosphere to a predominantly $\mathrm{H}^{+}$plasmasphere. The different scale heights of the constituent $\mathrm{O}^{+}$and $\mathrm{H}^{+}$profiles cause the gradient of the vertical $N_{\mathrm{e}}$ profile to increase sharply. Since it is always above the F2-peak, this height can serve as a base for finding the relative quantity of $\mathrm{H}^{+}$and $\mathrm{O}^{+}$ions and be used as a reference point to anchor the $N_{\mathrm{e}}$ profile. The values of the UTH were determined using a neural network model described in Sibanda (2010). The neural network model is based on all the available Alouette- 1 \& 2 and ISIS- $1 \&-2$ topside sounder datasets and provides a global prediction of the UTH as a function of local time, geographic latitude and longitude, magnetic inclination, solar zenith angle, 12-month running mean of the sunspot number (Rz12), height of the F2 peak ( $h m \mathrm{~F} 2)$ and peak electron density $(N m \mathrm{~F} 2)$. The UTH was estimated from each $N_{\mathrm{e}}$ profile by fitting robust regression lines at the bottom and the top parts of the profile on a logarithmic scale as shown on Fig. 2. The general assumption made is that the bottom part of the profile is influenced more by oxygen ion $\left(\mathrm{O}^{+}\right)$while the upper part is influenced more by the hydrogen ions $\left(\mathrm{H}^{+}\right)$. The UTH was then defined as the height at which the regression lines intersect. For the bottom part the regression line was fit to the points that lay above the height at which the lowest gradient of the measured $N_{\mathrm{e}}$ profile occurs in order to prevent the effects of the F-region recombination processes from influencing the gradient so that the derived gradient is assumed to be entirely due to $\mathrm{O}^{+}$scale height. Regression line fitting at the bottom part of the profile was done over the points such that the gradients do not exceed the lowest by $20 \%$ and for the top part the regression line was fitted to the points starting from the top downwards for which the gradients are not more than $20 \%$ less than the highest. The model provided 


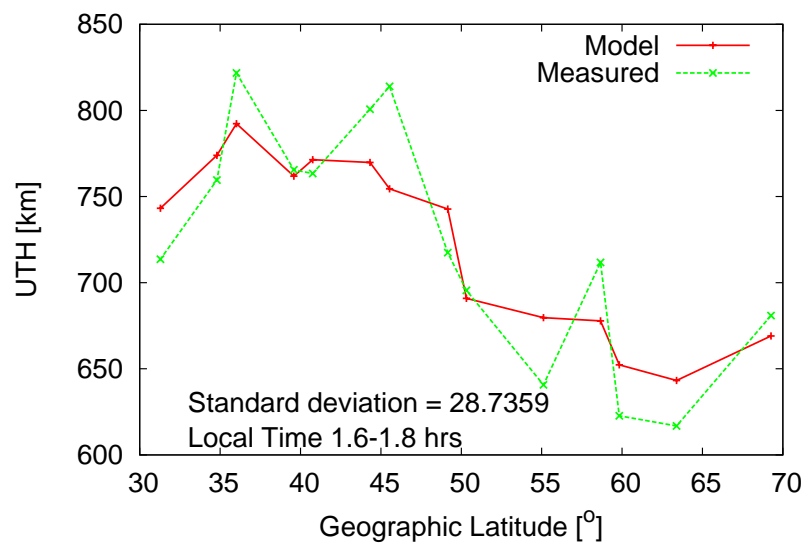

(a) Day 20, year 1978

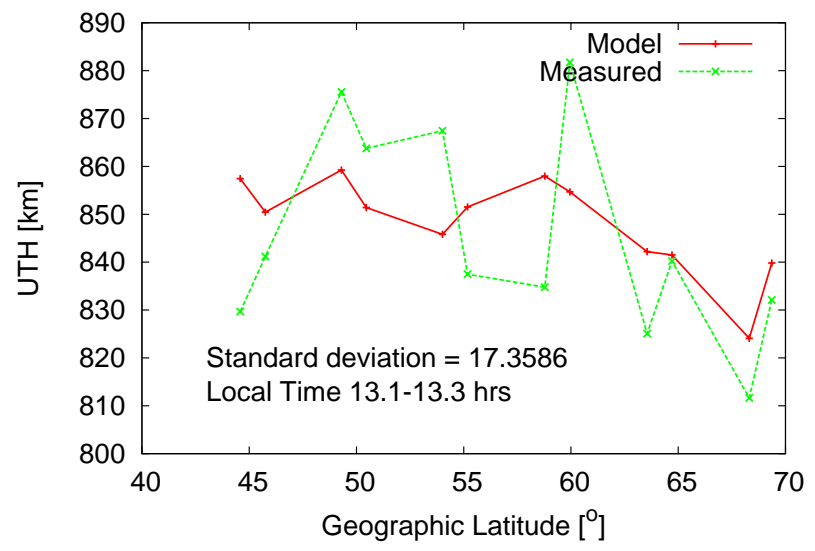

(c) Day 174, year 1978

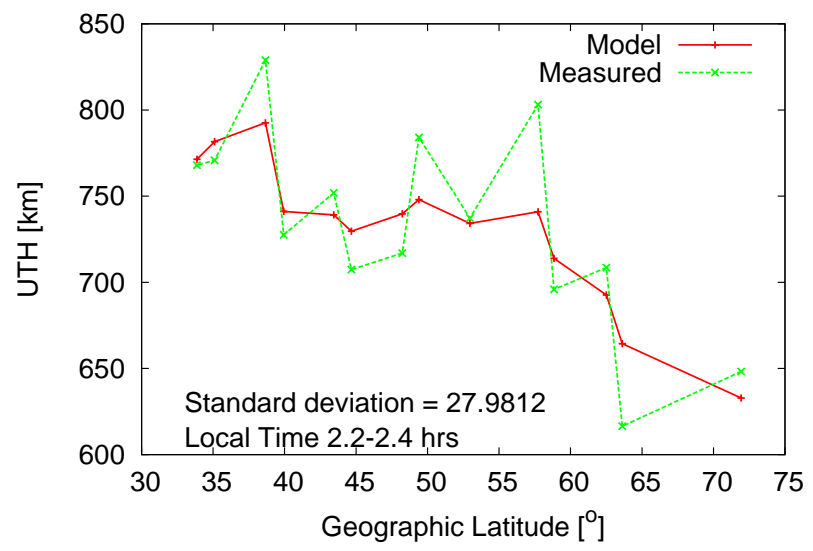

(b) Day 21, year 1978

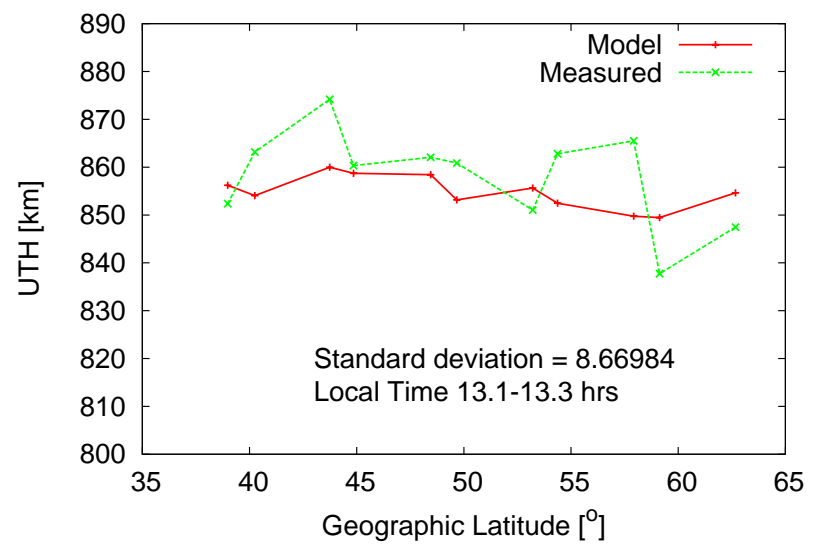

(d) Day 180, year 1978

Fig. 3. Comparison between model and measured values for four snapshot measurements taken on the days indicated on each sub-caption. On the $\mathrm{x}$-axis is the geographic 1 atitude for the measurements. Indicated on each plot is the local time range over which the measurements were made as the satellite passed over the region indicated by the latitude range.

predictions that compare well with the measured values. Figure 3 shows a comparison between the model results and the measured values for four different days (days 20, 21174 and 180 in 1978). The first two plots (a \& b) are for nighttime snapshot measurements during the summer period while the last two plots (c \& d) are for daytime measurements during the winter time. Indicated on each plot is the standard deviation of the model from the measured data indicating an estimate of how the model deviates from the measurements. The data points are taken at different latitude points along the path of the satellite over a time period (LT) indicated on each plot. The satellite data only provide measurements scattered along the path of the satellite separated in latitude by roughly $3-5^{\circ}$. The model provided UTH values that exhibit latitude and diurnal features comparable to those observed by Titheridge (1972).

Introducing the UTH into the procedure also ensures that the "effective scale height" (Liu et al., 2007) used in approximating the final $N_{\mathrm{e}}$ profile is not considered to be constant throughout the altitude range of the topside ionosphere.

\section{The reconstruction procedure}

Assuming that under most conditions helium ions have little effect on the electron density profiles (Carlson and Gordon, 1966) their presence can be neglected. The major ion species present in the topside ionosphere, therefore, are the hydrogen and oxygen ions (Titheridge, 1972). The $N_{\mathrm{e}}$ can thus be expressed as a sum of the constituent $\mathrm{O}^{+}$and the $\mathrm{H}^{+}$density profiles as:

$$
N_{\mathrm{e}}(h)=N_{\mathrm{O}^{+}}(h)+N_{\mathrm{H}^{+}}(h)
$$

The Epstein functions are used to analytically approximate the density distributions of the individual $\mathrm{O}^{+}$and $\mathrm{H}^{+}$. Thus, the reconstruction formula for the $N_{\mathrm{e}}$ as a function of altitude (h) is given by:

$$
\begin{aligned}
N_{\mathrm{e}}(h)= & N_{\mathrm{O}^{+}}(h m \mathrm{~F} 2) \operatorname{sech}^{2}\left(\frac{h-h m \mathrm{~F} 2}{2 H_{\mathrm{O}^{+}}}\right) \\
& +N_{\mathrm{H}^{+}}(h m \mathrm{~F} 2) \operatorname{sech}^{2}\left(\frac{h-h m \mathrm{~F} 2}{2 H_{\mathrm{H}^{+}}}\right)
\end{aligned}
$$


where $N_{\mathrm{O}^{+}}(h m \mathrm{~F} 2)$ and $N_{\mathrm{H}^{+}}(h m \mathrm{~F} 2)$ are the respective oxygen and hydrogen densities at the F2-peak, $\mathrm{H}_{\mathrm{O}^{+}}$and $\mathrm{H}_{\mathrm{H}^{+}}$ are the oxygen and hydrogen scale heights respectively. Equation (3) has four unknowns, namely: $N_{\mathrm{O}^{+}}(h m \mathrm{~F} 2)$, $N_{\mathrm{H}^{+}}(h m \mathrm{~F} 2), H_{\mathrm{O}^{+}}$and $H_{\mathrm{H}^{+}}$.

Theoretically, the plasma scale height for the $j$-th ion is defined as given in Eq. (4) (Liu et al., 2007)

$H_{j}=k T_{j} / m_{j} g$

where $k$ is the Boltzman's constant, $g$ is the acceleration due to gravity, $m_{j}$ is the ion mass and $T_{j}$ is the ion temperature. Following this definition and assuming isotropic conditions and equal ion temperatures, the $H_{\mathrm{H}^{+}}$will be approximately 16 times larger than the $H_{\mathrm{O}^{+}}$along a geomagnetic field line. Thus,

$H_{\mathrm{H}^{+}} \approx 16 H_{\mathrm{O}^{+}}$

It should be noted here that this holds only if scale heights are calculated along geomagnetic field lines. However, in this case, at low to mid latitudes, the scale heights are required in the vertical direction, thus the ratio does not stay the same (Kutiev and Marinov, 2007). The vertical scale heights were mapped to the field aligned scale heights at each calculation point via the geometry of the geomagnetic field which in effect, distributes the plasma density in the vertical direction. Thus, a correction factor was calculated by simple geometrical considerations of the magnetic inclination $(I)$ and the differential element along a magnetic field line $(d s)$ such that, the differential element in the vertical is $d h=\sin I d s$ (Stankov et al., 2003). Using the relationship between the magnetic dip-latitude and the inclination for a dipole, given by $\tan \lambda=1 / 2 \tan I$ (Chapman, 1963) where $\lambda$ is the magnetic dip-latitude, the correction factor is given by:

$\tau=\sin (\arctan [2 \tan (\lambda)])$

Applying Eq. (6) in (5) and substituting into Eq. (3) yields

$$
\begin{aligned}
N_{\mathrm{e}}(h)= & N_{\mathrm{O}^{+}}(h m \mathrm{~F} 2) \operatorname{sech}^{2}\left(\frac{h-h m \mathrm{~F} 2}{2 H_{\mathrm{O}^{+}}}\right) \\
& +N_{\mathrm{H}^{+}}(h m \mathrm{~F} 2) \operatorname{sech}^{2}\left(\frac{h-h m \mathrm{~F} 2}{32 \tau H_{\mathrm{O}^{+}}}\right)
\end{aligned}
$$

Integrating Eq. (7) from $h m \mathrm{~F} 2$ to infinity yields Eq. (8) (Stankov and Muhtarov, 2001; Stankov et al., 2002) for the topside TEC $\left(\mathrm{TEC}_{\mathrm{t}}\right)$ :

$\mathrm{TEC}_{\mathrm{t}}=2 H_{\mathrm{O}^{+}} N_{\mathrm{O}^{+}}(h m \mathrm{~F} 2)+32 \tau H_{\mathrm{O}^{+}} N_{\mathrm{H}^{+}}(h m \mathrm{~F} 2)$

The UTH and the F2-peak provide reference points to anchor the profile and simplify the reconstruction problem.

- At the UTH the $\mathrm{O}^{+}$and $\mathrm{H}^{+}$ion densities are equal, a condition represented by:

$$
\begin{aligned}
N_{\mathrm{O}^{+}}(h m \mathrm{~F} 2) \operatorname{sech}^{2}\left(\frac{\mathrm{UTH}-h m \mathrm{~F} 2}{2 H_{\mathrm{O}^{+}}}\right) \\
=N_{\mathrm{H}^{+}}(h m \mathrm{~F} 2) \operatorname{sech}^{2}\left(\frac{\mathrm{UTH}-h m \mathrm{~F} 2}{32 \tau H_{\mathrm{O}^{+}}}\right)
\end{aligned}
$$

- At the F2 layer peak, the sum of the $\mathrm{O}^{+}$and $\mathrm{H}^{+}$ion densities is equal to the measured peak $N_{\mathrm{e}}(N m \mathrm{~F} 2)$ following the condition of quasi-neutrality. This condition is shown in Eq. (10):

$$
N m \mathrm{~F} 2=N_{\mathrm{O}^{+}}(h m \mathrm{~F} 2)+N_{\mathrm{H}^{+}}(h m \mathrm{~F} 2)
$$

Equations (8), (9) and (10) form a system of three equations with three unknown parameters: $N_{\mathrm{O}^{+}}(h m \mathrm{~F} 2), N_{\mathrm{H}^{+}}(h m \mathrm{~F} 2)$ and $H_{\mathrm{O}^{+}}$. Three key inputs $\left(N m \mathrm{~F} 2, \mathrm{TEC}_{\mathrm{t}}\right.$ and the $\left.\mathrm{UTH}\right)$ are determined from the data sources described above. This system of equations was solved numerically using MATLAB's symbolic math and optimisation toolboxes to obtain the unknowns. Inserting the retrieved parameters into Eq. (7), the $N_{\mathrm{e}}$ as a function of altitude can then be calculated giving the vertical shape of the profile. This procedure is effectively a representation of the final $N_{\mathrm{e}}$ profile in terms of two Epstein steps one centered at the lower and the other at the upper limit of the height range considered. Shown on Fig. 5 is a case for the midday profile given in Fig. $4 \mathrm{~b}$ which shows the retrieved $N_{\mathrm{e}}$ profile plotted together with the profiles of the individual ions. The $\mathrm{O}^{+}$profile fits to the lower part and the $\mathrm{H}^{+}$profile fits to the upper part of the $N_{\mathrm{e}}$ profile.

\section{Results and analysis}

The described reconstruction procedure was performed using the GPS and ionosonde data from the Grahamstown $\left(33.3^{\circ} \mathrm{S}\right.$, $26.5^{\circ} \mathrm{E}$ ) ionospheric station to produce the $N_{\mathrm{e}}$ as a function of altitude. Figure 4 shows how the reconstructed profiles compare with the IRI-2007 model (Bilitza, 1990) and the topside model used in the ionosonde scaling software (Huang and Reinisch, 1996) for the different scenarios. Each plot represents a different local time corresponding to morning (06:00 LT), daytime (12:00 LT), evening (18:00 LT) and nighttime (00:00 LT) on 4 April 2005. This study focused on reconstructing the vertical structure of $N_{\mathrm{e}}$ to appear correctly at each altitude level. The diurnal, seasonal, latitudinal, solar activity and geomagnetic activity dependence of the reconstructed profiles are contained within the input parameters (GPS and ionosonde measurements and the UTH values) which are specific for a given scenario, and thus provide a unique $N_{\mathrm{e}}$ profile.

This analysis shows how the reconstructed $N_{\mathrm{e}}$ profiles compare with those from the models commonly used to predict the topside in the South African region. The shape of the reconstructed profiles show a sharp change in gradient around the transition region where the profile changes shape while that of the the IRI 2007 model has a gradual change in the gradient. In comparison with the ionosonde results on the other hand, shows that the retrieved electron densities are always higher than the ionosonde results for all altitudes.

These results demonstrate that the $N_{\mathrm{e}}$ profile can be reconstructed from its integral quantity, TEC, showing the smooth 


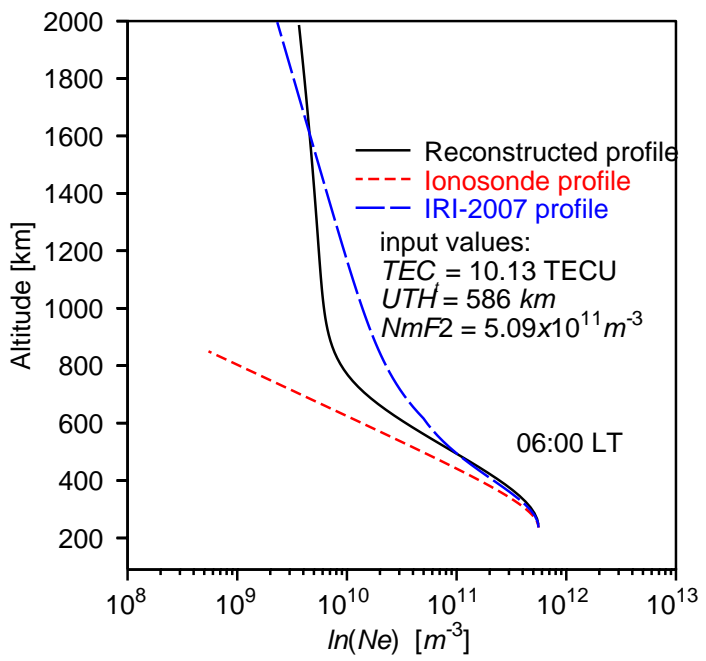

(a) Morning sector

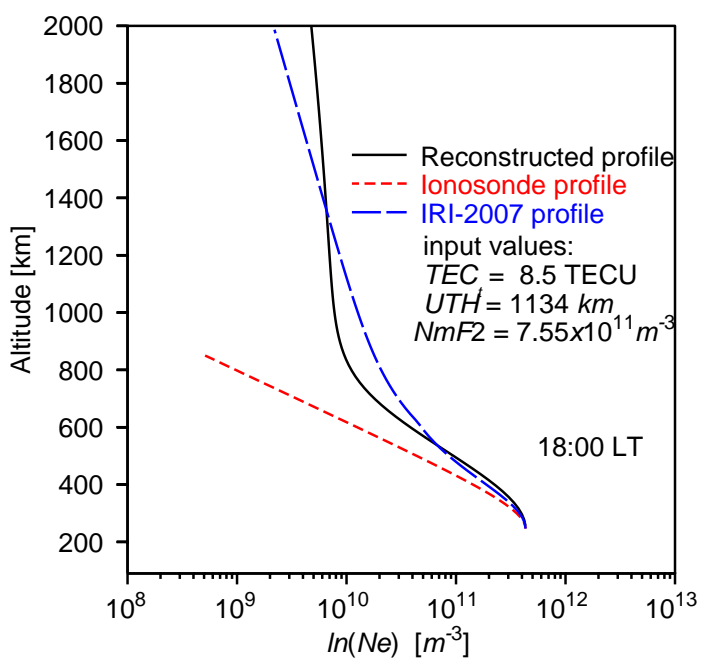

(c) Evening sector

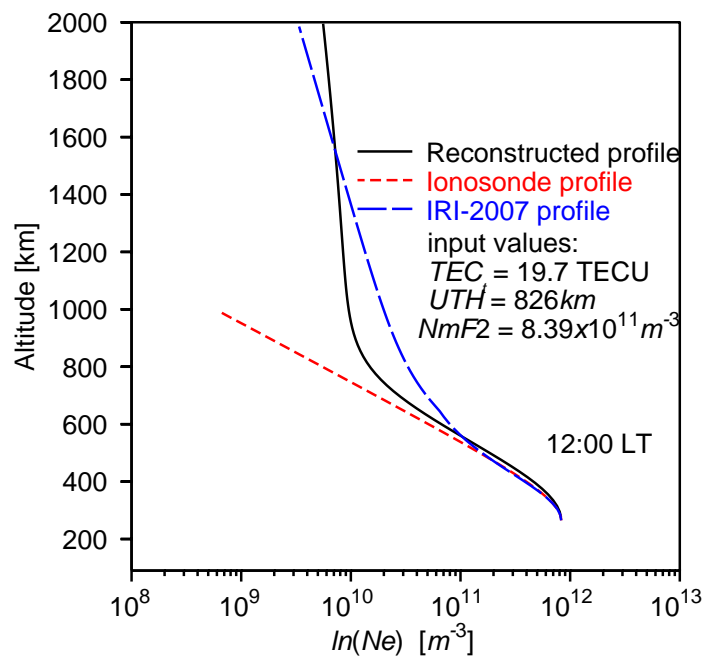

(b) Daytime sector

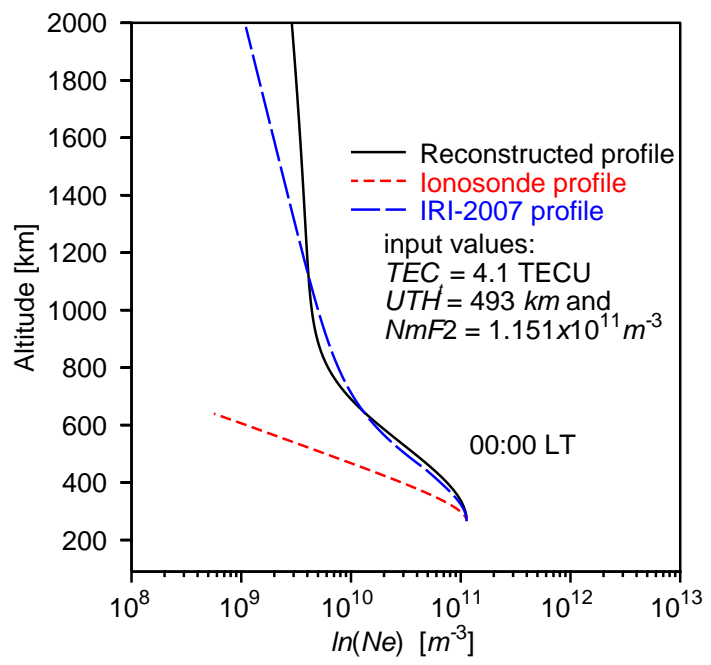

(d) Nighttime sector

Fig. 4. Reconstructed topside $N_{\mathrm{e}}$ profiles for morning (a), daytime (b), evening (c) and nighttime (d) sectors compared with the corresponding ionosonde profiles and the IRI-2007 model profiles. Values for the input parameters used are indicated in each plot.

and continuous decrease of the $N_{\mathrm{e}}$ with altitude in a comparable way to other empirically obtained profiles. This approach offers an opportunity to improve topside modeling efforts and provide valuable information about the topside ionosphere, a region that is difficult to model due to the scarcity of measured data. The approach has the advantage that the constructed profile is tied to reliable measured TEC values, offering a higher level of confidence in the resulting $N_{\text {e }}$ profiles. In addition, the method allows the inclusion of the UTH, an important parameter of the topside ionosphere that is useful in determining the shape of the $N_{\mathrm{e}}$ height profile. Using the UTH, to an extent, helps circumvent the shortcoming that arises from the use of a constant scale height for the entire altitude range of the topside ionosphere since the final $N_{\mathrm{e}}$ profile is presented in terms of two Epstein steps.
The scale height is a key parameter in determining the shape of ionospheric $N_{\mathrm{e}}$ profiles in the profiler functions such as the Epstein function (Liu et al., 2006; Stankov et al., 2003). It is defined (Eq. 4) in terms of the ion and electron temperatures which increase with altitude (Kutiev and Marinov, 2007) and therefore, it also varies with altitude. A more accurate approximation of the topside profile requires the construction of a suitable scale height function that represents the altitude variation of the scale height. The UTH provides an additional ionospheric parameter to anchor the profile.

It must be noted that the correction factor applied in Eq. (7) holds in the low and midlatitude regions where it is safe to assume that plasma remains attached to the magnetic field lines and co-rotates with the Earth (Webb and Essex, 2000). At higher latitudes on the other hand, the electric fields in 


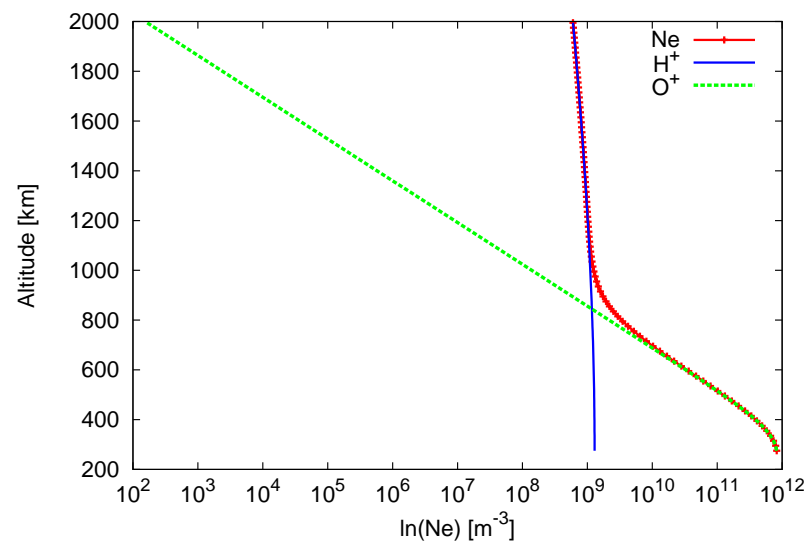

Fig. 5. Profiles of the $\mathrm{O}^{+}$and $\mathrm{H}^{+}$densities plotted together with the resulting $N_{\mathrm{e}}$.

the Earth's magnetosphere cause the plasma to move from one field line to another. This results in a reduced $\mathrm{H}^{+}$profile at high latitudes due to the plasmapause shape and density distribution in outer plasmasphere (Titheridge, 1972). Since the correction factor makes the $\mathrm{H}^{+}$scale height to increase from low to higher latitudes this therefore, contradicts the fact that the $\mathrm{H}^{+}$scale height must be lower at high latitudes. A subject of future study should involve deriving a method to adapt the technique for high latitude regions where the correction factor becomes excessively large.

\section{Conclusion}

The study has demonstrated that while TEC simply represents the integral of the $N_{\mathrm{e}}$ along the path, it can be useful in providing information about the spatial variation of $N_{\mathrm{e}}$ along the path caused by irregular structures in the ionosphere.

The results presented show that this approach can be used to characterise the topside ionospheric $N_{\mathrm{e}}$ over the South African region, where measured data are sparse and does not properly represent the various geophysical conditions. Using the data from the four ionosondes in South Africa and the dense network of GPS receivers shown in Fig. 1, the procedure can be expanded in longitude and latitude to provide a mapping of the entire region. GPS-TEC based techniques offer a promising tool for ionospheric characterisation. They provide a combination of dense global coverage, and the capability to give continuous measurements of TEC values, as well as being a relatively inexpensive technique. Future work should involve applying the technique at a location with an ionosonde co-located with a GPS receiver for which there also exists measured topside profiles. This would show how the calculated profiles compare with actual measurements. Should it become possible to validate this technique with topside measurements, the procedure could be refined for use over the African regions that currently lack ionospheric data, but have the possibility to install GPS receivers.

Acknowledgements. The authors acknowledge the support of the South African National Research Foundation (NRF) for the funding that made this work possible. This work was conducted at the Hermanus Magnetic Observatory and the compilation of the paper was completed at the University of Michigan, the authors therefore wish to thank Mark Moldwin for the support he provided during the compilation of the paper.

Topical Editor K. Kauristie thanks L. Liu and I. Kutiev for their help in evaluating this paper.

\section{References}

Benson, R. F., Reinisch, B. W., Green, J. L., Fung, S. F., Calvert, W., Haines, D. M., Bougeret, J. L., Manning, R., Carpenter, D. L., Gallagher, D. L., Reiff, P., and Taylor, W. W. L.: Magnetospheric radio sounding on the IMAGE mission, Radio Science Bulletin, 285, 9-20, 1998.

Bilitza, D.: International Reference Ionosphere, Tech. rep., NSSDC 90-92. WDC-A R\&S, Greenbelt, Maryland, USA, 1990.

Booker, H. G.: Fitting of multi-region ionospheric profiles of electron density by a single analytic function of height, J. Atmos. Terr. Phys., 39, 619-623, 1977.

Carlson, H. C. and Gordon, W. E.: Radar spectrographic estimates of ionic composition from $225-1400 \mathrm{~km}$ for solar minimum winter and summer conditions, J. Geophys. Res., 71, 5573-5578, 1966.

Chapman, S.: Geomagnetic nomenclature, J. Geophys. Res., 68, 1174, 1963.

Davies, K. and Hartmann, G. K.: Studying the ionosphere with the Global Positioning System, Radio Sci., 32, 1695-1703, 1997.

Depuev, V. H. and Pulinets, S. A.: A global empirical model of the ionospheric topside electron density, Adv. Space Res., 34, 20162020, 2004.

Hajj, G. A. and Romans, L. J.: Ionospheric electron density profiles obtained with the Global Position System: Results from the GPS/MET experiment, Radio Sci., 33, 175-190, 1998.

Huang, X. and Reinisch, B. W.: Vertical electron density profiles from the Digisonde network, Adv. Space Res., 18, 21-29, 1996.

Huang, X. Q. and Reinisch, B. W.: Vertical electron content from ionograms in real time, Radio Sci., 36, 335-342, 2001.

Huang, X., Reinisch, B. W., Bilitza, D., and Benson, R. F.: Electron density profiles of the topside ionosphere, Annals of Geophysics, 45, 125-130, 2002.

Jakowski, N., Kutiev, I. S., Heise, S., and Wehrenpfennig, A.: A Topside Ionosphere/Plasmasphere Model for Operational Applications, in: proceedings of the XXVII URSI Gerneral assembly, Maastricht, 2002.

Jakowski, N., Leitinger, R., and Angling, M.: Radio occultation techniques for probing the ionosphere, Annals of Geophysics, 47, 1049-1066, 2004.

Kutiev, I. and Marinov, P.: Topside sounder model of scale height and transition height characteristics of the ionosphere, Adv. Space Res., 39, 759-766, 2007.

Liu, L., Wan, W., and Ning, B.: A study of the ionogram derived effective scale height around the ionospheric $h m \mathrm{~F} 2$, Ann. Geophys., 24, 851-860, doi:10.5194/angeo-24-851-2006, 2006. 
Liu, L., Le, H., Wan, W., Sulzer, M. P., Lei, J., and Zang, M. L.: Analysis of the scale height in the lower topside ionosphere based on the Arecible incoherent scatter radar measurements, J. Geophys. Res., 112, A06307, doi:10.1029/2007JA012250, 2007.

Opperman, B. D. L.: Reconstructing ionospheric TEC over South Africa using signals from a regional GPS network, $\mathrm{PhD}$ thesis, Rhodes University, Grahamstown, South Africa, 2007.

Opperman, B. D. L., Cilliers, P. J., McKinnell, L. A., and Haggard, R.: Development of a regional GPS-based ionospheric TEC model for South Africa, Adv. Space Res., 39, 808-815, 2007.

Pulinets, S., Depuev, V., Karpachev, A., Radicella, S., and Danilkin, N.: Recent advances in topside profile modelling, Adv. Space Res., 29, 815-823, 2002.

Radicella, S. M. and Leitinger, R.: The evolution of the DGR approach to model the electron density profiles, Adv. Space Res., 27, 35-40, 2001.

Rama Rao, P. V. S., Gopi Krishna, S., Niranjan, K., and Prasad, D. S. V. V. D.: Temporal and spatial variations in TEC using simultaneous measurements from the Indian GPS network of receivers during the low solar activity period of 2004-2005, Ann. Geophys., 24, 3279-3292, doi:10.5194/angeo-24-3279-2006, 2006.

Reinisch, B. W. and Huang, X. Q.: Deducing topside profiles and total electron content from bottomside ionograms, Adv. Space Res., 27, 23-30, 2001.

Sibanda, P.: Challenges in topside ionospheric modelling over South Africa, Ph.D. thesis, Rhodes University, Grahamstown, South Africa, 2010.

Sibanda, P. and McKinnell, L. A.: The applicability of existing topside ionospheric models to the South African region, South African Journal of Science, 105, 387-390, 2009.
Stankov, S. M. and Muhtarov, P. Y.: Reconstruction of the electron density profile from the total electron content using upper transition level and vertical incidence sounding measurements, Comptes Rendus de l'Academie Bulgare Scinces, 54, 45-48, 2001.

Stankov, S. M., Warnant, R., and Jodogne, J. C.: Operational model for real-time reconstruction of the electron density profile using GPS-TEC measurements, in: proceedings of the XXVII URSI General Assembly, Maastricht, The Netherlands, pp. 1571-1574, 2002.

Stankov, S. M., Jakowski, N., Heise, S., Muhtarov, P., Kutiev, I., and Warnant, R.: A new method for reconstruction of the vertical electron density distribution in the upper ionosphere and plasmasphere, J. Geophys. Res., 108, 1164, doi:10.1029/ 2002JA009570, 2003.

Sutton, E. and Na, H.: A block iterative algorithm for tomographic reconstruction of ionospheric electron density, International Journal of Imaging Systems and Technology, 7, 238-245, 1996.

Titheridge, J. E.: Determination of ionospheric electron content from the faraday rotation of geostationery satellite signals, Planet. Space Sci., 20, 353-369, 1972.

Webb, P. A. and Essex, E. A.: An ionosphere-plasmasphere Global Electron Density model, Phys. Chem. Earth, 25, 301-306, 2000.

Yizengaw, E., Dyson, P. L., and Essex, E. A.: A study of the spatial density distribution in the topside ionosphere and plasmasphere using the FedSat GPS receiver, Adv. Space Res., 38, 2318-2323, 2006.

Yizengaw, E., Moldwin, M. B., Dyson, P. L., and Essex, E. A.: Using tomography of GPS TEC to routinely determine ionospheric average electron density profiles, J. Atmos. Solar-Terr. Phys., 69, 314-321, 2007. 